\title{
Chronic Physical Conditions, Multimorbidity, and Mild Cognitive Impairment in Low- and Middle-Income Countries
}

\author{
Ai Koyanagi, MD, ${ }^{a b}$ (D) Elvira Lara, PhD, ${ }^{b c}$ Brendon Stubbs, PhD, ${ }^{\text {def }}$ Andre F. Carvalho, PhD, ${ }^{g}$ \\ Hans Oh, PhD, ${ }^{h}$ Andrew Stickley, PhD ${ }^{i}$ Nicola Veronese, PhD, ${ }^{j k}$ and Davy Vancampfort, PhD ${ }^{l m}$
}

OBJECTIVES: To assess the association between chronic physical conditions and multimorbidity and mild cognitive impairment (MCI) in low- and middle-income countries (LMICs).

DESIGN: Nationally representative, cross-sectional, community-based study.

SETTING: Six countries that participated in the World Health Organization Study on Global Ageing and Adult Health.

PARTICIPANTS: Individuals aged 50 and older ( $\mathrm{N}=32,715$; mean age $62.1 \pm 15.6 ; 51.7 \%$ female).

MEASUREMENTS: The definition of MCI was based on the recommendations of the National Institute on Ageing and Alzheimer's Association. Ten chronic conditions were assessed (angina pectoris, arthritis, asthma, cataract, chronic lung disease, diabetes mellitus, edentulism, hearing problems, hypertension, stroke). Multivariable logistic regression analysis was conducted to assess the association

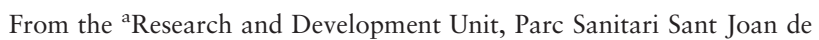
Déu, Universitat de Barcelona, Fundació Sant Joan de Déu, Barcelona, Spain; ' Instituto de Salud Carlos III, Centro de Investigación Biomédica en Red de Salud Mental, Madrid, Spain; ${ }^{\circ}$ Department of Psychiatry, Universidad Autónoma de Madrid, Madrid, Spain; ${ }^{\mathrm{d}}$ Physiotherapy Department, South London and Maudsley National Health Service Foundation Trust, Denmark Hill, London, United Kingdom; ${ }^{\text {eHealth }}$ Service and Population Research Department, Institute of Psychiatry, Psychology and Neuroscience, King's College London, London, United Kingdom; fFaculty of Health, Social Care and Education, Anglia Ruskin University, Chelmsford, United Kingdom; 'Department of Clinical Medicine and Translational Psychiatry Research Group, Faculty of Medicine, Federal University of Ceará, Fortaleza, Brazil; hSchool of Social Work, University of Southern California, Los Angeles, California; ${ }^{i}$ Stockholm Center for Health and Social Change, Södertörn University, Huddinge, Sweden; i Geriatrics Unit, Department of Geriatric Care, OrthoGeriatrics and Rehabilitation, E.O. Galliera Hospital, National Relevance and High Specialization Hospital, Genova, Italy; ${ }^{\mathrm{N}}$ National Research Council, Neuroscience Institute, Aging Branch, Padova, Italy;

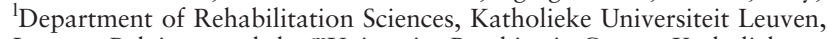
Leuven, Belgium; and the ${ }^{\mathrm{m}}$ University Psychiatric Center, Katholieke Universiteit Leuven, Leuven-Kortenberg, Belgium.

Address correspondence to Ai Koyanagi, MD, MSc, PhD, Research and Development Unit, Parc Sanitari Sant Joan de Déu, Universitat de Barcelona, Fundació Sant Joan de Déu, Dr. Antoni Pujadas, 42, Sant Boi de Llobregat, Barcelona, Spain. E-mail: a.koyanagi@pssjd.org

DOI: $10.1111 /$ jgs. 15288 between chronic physical conditions, multimorbidity $(\geq 2$ chronic conditions), and MCI.

RESULTS: The prevalence of multimorbidity was $49.8 \%$ (95\% confidence interval $(\mathrm{CI})=48.1-51.5 \%)$ and of MCI was $15.3 \%(95 \% \mathrm{CI}=14.4-16.3 \%)$. After adjustment for potential confounders, edentulism (odds ratio $(\mathrm{OR})=1.24)$, arthritis $(\mathrm{OR}=1.24)$, chronic lung disease $(\mathrm{OR}=1.29)$, cataract $(\mathrm{OR}=1.33)$, stroke $(\mathrm{OR}=1.94)$, hearing problems $(\mathrm{OR}=2.27)$, and multimorbidity $(\mathrm{OR}=1.40)$ were significantly associated with $\mathrm{MCI}$. There was a gradual increase in the likelihood of MCI (1 condition: $\mathrm{OR}=1.21,95 \% \mathrm{CI}=1.03-1.42 ; \geq 4$ conditions: $\mathrm{OR}=2.07$, $95 \% \mathrm{CI}=1.70-2.52$ ).

CONCLUSION: These results highlight the need to investigate the underlying mechanisms linking chronic conditions and MCI and whether prevention or treatment of chronic conditions or multimorbidity can reduce the onset of cognitive decline and subsequent dementia, especially in LMICs. J Am Geriatr Soc 66:721-727, 2018.

Key words: mild cognitive impairment; chronic physical conditions; multimorbidity; low- and middle-income countries

$\mathrm{T}$ he world population is aging at an unprecedented speed because of increasing life expectancy. The number of individuals aged 65 and older is projected to increase from 524 million in 2010 to 1.5 billion by 2050 , with most of the increase occurring in low- and middleincome countries (LMICs). ${ }^{1}$ Increases in noncommunicable diseases (NCDs) such as heart disease, cancer, and diabetes mellitus ${ }^{1}$ and neuropsychiatric disorders such as dementia $^{2}$ will inevitably accompany this demographic change. In particular, dementia is projected to increase sharply because the incidence of dementia doubles with every 6.3-year increase in age in the older population. ${ }^{3}$ The number of people living with dementia is projected to increase from current figures of 46 million to 131.5 
million by $2050{ }^{3}$ The proportion of people with dementia residing in LMICs is expected to increase from current rates of $58 \%$ to $68 \%$ in $2050 .^{3}$

Dementia is one of the major causes of disability and dependency in older adults and has significant social and economic effects, ${ }^{4}$ but there are no drugs to cure dementia or to modify its clinical course, and symptomatic medication has only modest effects. ${ }^{5,6}$ Thus, identifying modifiable risk factors of the precursory stage of dementia to establish interventions to prevent or delay the onset of dementia is a priority. Specifically, mild cognitive impairment (MCI) is considered to be a preclinical transitional state of dementia ${ }^{7}$ for which targeted interventions may be feasible. The conversion rate of MCI to dementia has been estimated to be $12 \%$ at 1 year, $20 \%$ at 3 years, and $50 \%$ at 5 years. ${ }^{8}$ Previously reported potentially modifiable risk factors for MCI include factors such as low physical activity, obesity, diabetes mellitus, and hypertension.?

In terms of single chronic physical diseases, most previous studies have focused on cardiometabolic diseases, ${ }^{10}$ but studies of other chronic conditions are limited. Furthermore, there is a notable paucity of data on the association between multimorbidity (coexistence of $\geq 2$ chronic conditions) and MCI. Multimorbidity is highly prevalent in the older population and is an important risk concept because it is associated with greater disability, poorer quality of life, polypharmacy, premature mortality, and higher healthcare costs. ${ }^{11,12}$

To our knowledge, only a few studies have specifically focused on the association between multimorbidity and $\mathrm{MCI}$ in the general population. ${ }^{13,14}$ One U.S. longitudinal study found that individuals aged 70 and older with multimorbidity had a risk of MCI or dementia that was 1.38 (95\% confidence interval $(\mathrm{CI})=1.05-1.82)$ times as high than in those without multimorbidity $(\mathrm{N}=2,176)$. Another cross-sectional study from Sweden found that individuals aged 75 and older with 2 or 3 chronic conditions are 3.03 $(95 \% \mathrm{CI}=1.20-7.64)$ times as likely to have $\mathrm{MCI}$ as those with no conditions $(\mathrm{N}=1,435) .{ }^{14}$ These studies were conducted in limited locations in single high-income countries with a focus on elderly adults. Thus, it is unknown whether these results are applicable to other age groups or settings. Assessment of cognitive function and its risk factors at earlier ages is important from the point of view of prevention of dementia because cognitive dysfunction appears up to 10 years before dementia diagnosis, ${ }^{15}$ and it is important to intervene in midlife. ${ }^{16-18}$ Also, data on this topic from LMICs are particularly important given that increasing trends in cardiovascular diseases coupled with epidemics of obesity and increasing hypertension can result in upward trends in dementia prevalence and incidence in this setting. ${ }^{3}$ Furthermore, the association between multimorbidity and MCI may differ in LMICs because of different disease profiles, population age structure, and healthcare systems, as well as higher prevalence of poverty and low education and suboptimal treatment of chronic conditions. ${ }^{19}$

Thus, the main aim of the current study was to assess the association between multimorbidity and MCI in adults aged 50 and older in 6 LMICs using data from the World Health Organization (WHO) Study on Global Ageing and Adult Health (SAGE).

\section{METHODS}

\section{The Survey}

Data from the SAGE survey were analyzed. This survey was undertaken in China, Ghana, India, Mexico, Russia, and South Africa between 2007 and 2010. Based on the World Bank classification at the time of the survey, all of these countries were LMICs. Details of the survey methodology have been published elsewhere. ${ }^{20}$ In brief, to obtain nationally representative samples, a multistage clustered sampling design method was used. The sample consisted of adults aged 18 and older, with oversampling of those aged 50 and older. Trained interviewers conducted faceto-face interviews using a standard questionnaire. Standard translation procedures were undertaken to ensure comparability between countries. Those who were unable to undertake the interview because of limited cognitive function were not included in the current study. Survey response rates were: $93 \%$ for China, $81 \%$ for Ghana, $68 \%$ for India, $53 \%$ for Mexico, $83 \%$ for Russia, and $75 \%$ for South Africa. Sampling weights were constructed to adjust for the population structure as reported by the United Nations Statistical Division. Ethical approval was obtained from the WHO Ethical Review Committee and local ethics research review boards. Written informed consent was obtained from all participants.

\section{MCI (Outcome)}

MCI was ascertained based on the recommendations of the National Institute on Aging and Alzheimer's Association. ${ }^{21}$ We applied algorithms identical to those used in previous publications using a dataset with the same survey questions to identify MCI. ${ }^{9,22}$ Briefly, individuals fulfilling all of the following conditions were considered to have MCI.

\section{Concern about a change in cognition}

Individuals who replied "bad" or "very bad" to the question, "How would you best describe your memory at present?" and those who answered "worse" to the question, "Compared with 12 months ago, would you say your memory is now better, the same, or worse then it was then?" were considered to have this condition.

\section{Objective evidence of impairment in one or more cog- nitive domains}

This was based on a cut-off of 1 standard deviation or more below the mean after adjustment for level of education, age, and country. Cognitive function was assessed according to word list immediate and delayed verbal recall from the Consortium to Establish a Registry for Alzheimer's Disease, ${ }^{23}$ which assessed learning and episodic memory; digit span forward and backward from the Weschler Adult Intelligence Scale, ${ }^{24}$ which evaluated attention and working memory; and the animal naming task, ${ }^{23}$ which assessed verbal fluency. 
Preservation of independence in select functional abilities (absence of severe or extreme activity of daily living difficulties)

This was assessed using questions on self-reported difficulties with basic activities of daily living (ADLs) in the past 30 days. ${ }^{25}$ Specific questions were: "How much difficulty did you have in getting dressed?" and "How much difficulty did you have with eating (including cutting up your food)?" Answer options were none, mild, moderate, severe, and extreme (cannot do). Those who answered none, mild, or moderate to both of these questions were considered to have preservation of independence in ADLs. Although these questions were about difficulty with ADLs rather than dependence, we assumed that those with severe or extreme levels of difficulty performing these tasks were highly unlikely to be independent in functional abilities. All other individuals were deleted from the analysis (935 individuals aged $\geq 50$ ).

\section{No dementia}

Individuals with a level of cognitive impairment severe enough that they could not take the survey were not included in the study.

\section{Chronic Conditions and Multimorbidity (Exposures)}

We included all 10 chronic physical conditions (angina pectoris, arthritis, asthma, cataract, chronic lung disease, diabetes mellitus, edentulism, hearing problems, hypertension, stroke), assessed according to self-report of diagnosis, symptoms, interviewer observation, and blood pressure measurement (see Supplementary Table S1 for details), for which data were available in SAGE. These conditions have been reported to be associated with poor cognitive performance. ${ }^{9,26-33}$ The total number of chronic conditions was calculated and categorized as $0,1,2,3$, and 4 or more. Multimorbidity was defined as 2 or more chronic conditions. $^{34}$

\section{Control Variables}

The analysis adjusted for a number of potential confounders that have been reported to be linked with MCI and chronic physical conditions. ${ }^{9,35,36}$ Sociodemographic control variables included age, sex, education (no formal, some primary, $\geq$ secondary completed), and wealth quintiles based on country-specific income. Other variables included health behavior (smoking (never, current, former), alcohol consumption (never, nonheavy, heavy), physical activity), body mass index (BMI) based on measured weight and height $(<18.5,18.5-24.9,25.0-29.9$, $\geq 30 \mathrm{~kg} / \mathrm{m}^{2}$ ), and depression. (See Supplementary Table S2 for details on these variables.)

\section{Statistical Analysis}

Statistical analysis was performed using Stata version 14.1 (Stata Corp LP, College Station, TX). The analysis was restricted to those aged 50 and older. The difference in the prevalence of multimorbidity or MCI according to sample characteristics was tested using chi-square tests. Tetrachoric correlations between each chronic condition were calculated in those with MCI.

We conducted multivariable logistic regression analysis to assess the association between number of chronic conditions, including multimorbidity $(\geq 2$ chronic conditions), or each of the 10 individual chronic conditions (exposure variables) and MCI (outcome) using the overall sample (aged $\geq 50$ ) and according to age group (50-64, $\geq 65$ ) because previous studies have shown that risk factors for MCI may differ between mid- and late life. ${ }^{9,37}$ Finally, to assess the degree of between-country heterogeneity in the association between multimorbidity and MCI, based on country-wise estimates, we calculated Higgin's $\mathrm{I}^{2}$, which represents the degree of heterogeneity that sampling error does not explain; a value of $25 \%$ is often considered as a low level of heterogeneity, $50 \%$ as moderate, and $75 \%$ as high. ${ }^{38}$

The regression analyses were all adjusted for age, sex, education, wealth, smoking, alcohol consumption, physical activity, BMI, depression, and country, with the exception of the country-wise analysis, which did not adjust for country. When the individual chronic conditions were the exposure variable, the models were also adjusted for the presence of other chronic illnesses to account for comorbid chronic conditions. This variable included information on whether the individual had any of the other 9 chronic conditions. Country adjustment was done by including dummy variables for each country. Less than $5 \%$ of the data was missing for the variables used in the analysis. All variables were included in the models as categorical variables, with the exception of age when used as a continuous variable. Complete-case analysis was performed. Sample weighting and the complex study design were taken into account in the analyses. Results from the regression analyses are presented as odds ratios (ORs) with $95 \%$ confidence intervals (CIs). The level of statistical significance was set at $\mathrm{P}<.05$.

\section{RESULTS}

The final analytical sample consisted of 32,715 individuals aged 50 and older (China, $\mathrm{n}=12,815$; Ghana, $\mathrm{n}=4,201$; India, $\mathrm{n}=6,191 ;$ Mexico, $\mathrm{n}=2,070$; Russia, $\mathrm{n}=3,766$; South Africa, $n=3,672$ ). Mean age was 62.1 , and $51.7 \%$ were female. The prevalence $(95 \% \mathrm{CI})$ of multimorbidity was $49.8 \%(95 \% \mathrm{CI}=48.1-51.5 \%)$ and of $\mathrm{MCI}$ was $15.3 \%(95 \% \mathrm{CI}=14.4-16.3 \%)$. The country-wise prevalence of individual chronic physical conditions is provided in Supplementary Table S3. Older age, female sex, lower levels of education and wealth, former smoking, low physical activity, BMI of $30 \mathrm{~kg} / \mathrm{m}^{2}$ or more, and depression were associated with greater prevalence of multimorbidity (Table 1).

All single chronic conditions assessed were significantly associated with higher prevalence of MCI with the exception of angina pectoris, cataract, and diabetes mellitus (Table 2). There was a linear increase in the prevalence of MCI with increasing number of chronic conditions. In individuals with MCI, there was a particularly strong correlation between angina pectoris and asthma, angina 


\section{Table 1. Prevalence of Multimorbidity According to} Sample Characteristic

\begin{tabular}{|c|c|c|c|}
\hline Characteristic & $\%^{\mathrm{a}}$ & With Multimorbidity, \% & P-Value \\
\hline Age & & & $<.001$ \\
\hline $50-59$ & 47.3 & 37.6 & \\
\hline $60-69$ & 30.2 & 53.1 & \\
\hline $70-79$ & 17.7 & 70.2 & \\
\hline$\geq 80$ & 4.8 & 74.6 & \\
\hline Sex & & & $<.001$ \\
\hline Female & 51.7 & 54.9 & \\
\hline Male & 48.3 & 44.4 & \\
\hline Education & & & $<.001$ \\
\hline No formal & 28.5 & 54.3 & \\
\hline Primary & 28.2 & 46.6 & \\
\hline$\geq$ Secondary completed & 43.3 & 49.0 & \\
\hline Wealth & & & .005 \\
\hline Poorest & 16.9 & 53.2 & \\
\hline Poorer & 18.9 & 53.1 & \\
\hline Middle & 19.4 & 50.0 & \\
\hline Richer & 21.5 & 48.0 & \\
\hline Richest & 23.3 & 46.3 & \\
\hline Smoking & & & $<.001$ \\
\hline Never & 58.7 & 51.0 & \\
\hline Current & 34.9 & 46.4 & \\
\hline Former & 6.4 & 57.4 & \\
\hline Alcohol consumption & & & $<.001$ \\
\hline Never & 66.7 & 49.0 & \\
\hline Nonheavy & 29.1 & 52.6 & \\
\hline Heavy & 4.2 & 39.8 & \\
\hline Low physical activity & & & $<.001$ \\
\hline No & 77.6 & 47.8 & \\
\hline Yes & 22.4 & 56.8 & \\
\hline \multicolumn{4}{|l|}{ Body mass index, $\mathrm{kg} / \mathrm{m}^{2}$} \\
\hline$<18.5$ & 16.2 & 52.1 & $<.001$ \\
\hline $18.5-24.9$ & 47.8 & 44.2 & \\
\hline $25.0-29.9$ & 24.5 & 51.4 & \\
\hline$\geq 30$ & 11.5 & 67.5 & \\
\hline Depression & & & $<.001$ \\
\hline No & 94.5 & 48.3 & \\
\hline Yes & 5.5 & 76.5 & \\
\hline
\end{tabular}

Percentage is based on weighted sample.

${ }^{\mathrm{a}}$ Denominator ranges from 31,179 to 32,715 .

pectoris and chronic lung disease, asthma and chronic lung disease, diabetes mellitus and hypertension, edentulism and hearing problems, and stroke and hypertension (Supplementary Table S4).

In the overall sample, multivariable regression analysis showed that all individual chronic conditions are associated with higher odds of MCI, but statistical significance was reached only for arthritis $(\mathrm{OR}=1.24)$, cataract $(\mathrm{OR}=1.33)$, chronic lung disease $(\mathrm{OR}=1.29)$, edentulism $(\mathrm{OR}=1.24)$, hearing problems $(\mathrm{OR}=2.27)$, and stroke $(\mathrm{OR}=1.94)$. The OR for multimorbidity was $1.40 \quad(95 \% \quad \mathrm{CI}=1.23-1.58)$ (Table 3). These associations were similar in the two age groups with the exception of angina pectoris and chronic lung disease, which were significantly associated with MCI only in the younger group. The association between MCI and multimorbidity showed a moderate level of betweencountry heterogeneity (Higgin's $\mathrm{I}^{2}=64 \%$, 95\% $\mathrm{CI}=12 \%-85 \%) \quad$ (Supplementary Figure S1). There was a gradual increase in the odds of MCI with increasing number of conditions in the overall sample ( 1 condition: $\mathrm{OR}=1.21$,
Table 2. Prevalence of Chronic Conditions and Proportion of Individuals with Mild Cognitive Impairment (MCI) According to Presence of Chronic Conditions

\begin{tabular}{|c|c|c|c|}
\hline Characteristic & $\%^{a}$ & With MCI, \% & P-Value \\
\hline Angina pectoris & & & .29 \\
\hline No & 82.8 & 15.1 & \\
\hline Yes & 17.2 & 16.3 & \\
\hline Arthritis & & & $<.001$ \\
\hline No & 71.0 & 14.2 & \\
\hline Yes & 29.0 & 17.9 & \\
\hline Asthma & & & .03 \\
\hline No & 92.5 & 15.1 & \\
\hline Yes & 7.5 & 17.9 & \\
\hline Cataract & & & .07 \\
\hline No & 73.6 & 14.9 & \\
\hline Yes & 26.4 & 16.5 & \\
\hline Chronic lung disease & & & $<.001$ \\
\hline No & 85.0 & 14.5 & \\
\hline Yes & 15.0 & 19.6 & \\
\hline Diabetes mellitus & & & .70 \\
\hline No & 93.3 & 15.3 & \\
\hline Yes & 6.7 & 15.8 & \\
\hline Edentulism & & & $<.001$ \\
\hline No & 87.8 & 14.7 & \\
\hline Yes & 12.2 & 20.0 & \\
\hline Hearing problems & & & $<.001$ \\
\hline No & 94.7 & 14.2 & \\
\hline Yes & 5.3 & 32.0 & \\
\hline Hypertension & & & $<.001$ \\
\hline No & 45.2 & 13.3 & \\
\hline Yes & 54.8 & 17.0 & \\
\hline Stroke & & & $<.001$ \\
\hline No & 97.3 & 15.0 & \\
\hline Yes & 2.7 & 27.6 & \\
\hline Number of chronic conditions & & & $<.001$ \\
\hline 0 & 19.2 & 10.7 & \\
\hline 1 & 31.0 & 14.0 & \\
\hline 2 & 23.6 & 15.4 & \\
\hline 3 & 13.8 & 18.0 & \\
\hline$\geq 4$ & 12.5 & 21.2 & \\
\hline
\end{tabular}

Percentage is based on weighted sample.

${ }^{a}$ Denominator ranges from 31,940 to 32,662 .

$95 \% \quad \mathrm{CI}=1.03-1.42 ; \quad \geq 4$ conditions: $\mathrm{OR}=2.07, \quad 95 \%$ $\mathrm{CI}=1.70-2.52$ ) (Table 4). In terms of other potentially modifiable risk factors for MCI, in the overall sample, smoking, low physical activity, and obesity (BMI $\geq 30.0 \mathrm{~kg} / \mathrm{m}^{2}$ ) were also associated with higher odds of MCI independent of the number of chronic conditions, although some of these factors were not significantly associated with $\mathrm{MCI}$ in one of the age groups (Table 4).

\section{DISCUSSION}

Several chronic conditions and multimorbidity were significantly associated with higher odds of MCI. There was also a gradual increase in the odds of MCI with increasing number of chronic conditions. The strength of the study includes the large sample size and the use of nationally representative samples from 6 countries, which comprise nearly half of the world population. ${ }^{20}$ Our study results expand understanding of the effects of modifiable risk factors on development of MCI and 
Table 3. Associations Between Physical Health Conditions and Multimorbidity and Mild Cognitive Impairment, Estimated Using Multivariable Logistic Regression

\begin{tabular}{|c|c|c|c|}
\hline \multirow[b]{2}{*}{ Chronic Physical Condition } & \multicolumn{3}{|c|}{ Odds Ratio (95\% Confidence Interval) } \\
\hline & Overall & Aged 50-64 & Aged $\geq 65$ \\
\hline Arthritis & $1.24(1.10-1.40)^{\mathrm{C}}$ & $1.24(1.06-1.44)^{b}$ & $1.30(1.09-1.54)^{b}$ \\
\hline Asthma & $1.18(0.96-1.45)$ & $1.13(0.85-1.50)$ & $1.22(0.91-1.63)$ \\
\hline Cataract & $1.33(1.15-1.55)^{\mathrm{c}}$ & $1.44(1.15-1.79)^{b}$ & $1.28(1.06-1.55)^{b}$ \\
\hline Edentulism & $1.24(1.03-1.48)^{\mathrm{a}}$ & $1.23(0.95-1.58)$ & $1.21(0.95-1.55)$ \\
\hline Hearing problems & $2.27(1.84-2.78)^{\mathrm{C}}$ & $2.86(2.10-3.89)^{\mathrm{C}}$ & $1.91(1.50-2.43)^{C}$ \\
\hline Hypertension & $1.08(0.96-1.20)$ & $1.04(0.91-1.19)$ & $1.15(0.97-1.37)$ \\
\hline Stroke & $1.94(1.49-2.53)^{\mathrm{C}}$ & $2.35(1.57-3.52)^{\mathrm{C}}$ & $1.65(1.14-2.39)^{b}$ \\
\hline Multimorbidity ${ }^{d}$ & $1.40(1.23-1.58)^{\mathrm{C}}$ & $1.43(1.25-1.64)^{\mathrm{C}}$ & $1.42(1.16-1.73)^{\mathrm{C}}$ \\
\hline
\end{tabular}

Models were adjusted for age, sex, education, wealth, body mass index, smoking, alcohol consumption, physical activity, depression, other physical illness, and country, with the exception of multimorbidity, which was not adjusted for other physical illness.

$\mathrm{p}<{ }^{\mathrm{a}} .05,{ }^{\mathrm{b}} .01,{ }^{\mathrm{c}} .001$.

$\mathrm{d}_{\geq 2}$ physical health conditions.

dementia by showing for the first time that multimorbidity is associated with MCI in midlife and in LMICs. This is an important finding because previous studies have suggested that strategies to address risk factors for dementia should take place in midlife. ${ }^{16-18}$ Furthermore, our study has important implications for public health in LMICs, where MCI and dementia are often underdiagnosed, ${ }^{39}$ health care is suboptimal, ${ }^{19}$ and there is urgent need for strategies to address and manage the growing epidemic of chronic diseases, ${ }^{40}$ which are also risk factors for MCI and dementia.

Angina pectoris (only in those aged 50-64), edentulism, arthritis, chronic lung disease, cataract, stroke, and hearing problems were significantly associated with higher odds of MCI. All these conditions have been observed to be associated with poor cognitive performance, even in study populations from LMICs, ${ }^{26,28-30,32,33,41-43}$ although with mixed results for some conditions. ${ }^{32,44,45}$ Similar to some previous studies, we did not observe a significant association between diabetes mellitus or hypertension and MCI. ${ }^{46,47}$ These two conditions have been recognized as potentially modifiable risk factors for dementia. ${ }^{16}$ Thus, further studies from LMICs are warranted to assess whether our results are corroborated. In particular, the results on diabetes mellitus may have differed if objective data such as blood glucose had been available.

Table 4. Association Between Number of Chronic Physical Conditions and Other Modifiable Factors and Mild Cognitive Impairment, Estimated Using Multivariable Logistic Regression

\begin{tabular}{|c|c|c|c|}
\hline Characteristic & Overall & Aged 50-64 & Aged $\geq 65$ \\
\hline 1 & $1.21(1.03-1.42)^{\mathrm{a}}$ & $1.23(1.02-1.48)^{\mathrm{a}}$ & $1.14(0.83-1.55)$ \\
\hline 2 & $1.37(1.14-1.63)^{\mathrm{C}}$ & $1.40(1.14-1.73)^{b}$ & $1.33(0.91-1.95)$ \\
\hline 3 & $1.75(1.43-2.14)^{\mathrm{C}}$ & $1.91(1.45-2.51)^{\mathrm{C}}$ & $1.66(1.21-2.27)^{b}$ \\
\hline Current & $1.20(1.01-1.43)^{\mathrm{a}}$ & $1.23(1.00-1.50)^{\mathrm{a}}$ & $1.24(0.91-1.69)$ \\
\hline Former & $1.20(0.97-1.50)$ & $1.16(0.86-1.58)$ & $1.22(0.88-1.69)$ \\
\hline \multicolumn{4}{|c|}{ Alcohol consumption (reference never) } \\
\hline Non-heavy & $0.97(0.82-1.15)$ & $1.03(0.85-1.26)$ & $0.95(0.73-1.23)$ \\
\hline Heavy & $1.22(0.93-1.61)$ & $1.18(0.81-1.72)$ & $1.31(0.86-2.00)$ \\
\hline Low physical activity & $1.24(1.08-1.43)^{b}$ & $0.83(0.69-1.00)$ & $1.72(1.40-2.11)^{\mathrm{C}}$ \\
\hline Depression & $0.93(0.69-1.24)$ & $0.87(0.61-1.25)$ & $0.90(0.57-1.44)$ \\
\hline
\end{tabular}

The model was mutually adjusted for all variables in the table, sociodemographic variables (age, sex, education, wealth), and country. $\mathrm{p}<{ }^{\mathrm{a}} .05, \stackrel{\mathrm{b}}{.01},{ }^{\mathrm{c}} .001$. 
Our study results are in line with those of previous studies reporting high risk of $\mathrm{MCI}$ in individuals with multiple chronic conditions. ${ }^{13,14,48}$ One study found that faster accumulation of chronic conditions was associated with greater decline in cognitive function. ${ }^{48}$ Multimorbidity may reflect an age-related multisystem failure, which can also be accompanied by neurodegeneration or cognitive decline. ${ }^{48}$ Some combinations of chronic conditions may act synergistically to accelerate cognitive decline, as in the case of heart disease and cerebrovascular disease, whereas polypharmacy and drug interactions may also increase the risk of cognitive decline in individuals with multimorbidity. ${ }^{13}$ One study found that several health problems not individually recognized as risk factors for dementia were associated with greater risk of dementia when combined into a frailty index. ${ }^{49}$ This finding, together with increasing evidence that multimorbidity is related to poor cognitive performance, reinforces the notion that promoting overall health of the population might mitigate the burden of late-life dementia. ${ }^{50}$ Finally, a moderate level of between-country heterogeneity in the association between multimorbidity and MCI was found. Although the reason for this heterogeneity is not clear, it may be related to factors such as access to health care and quality of care (e.g., availability of drugs). This is an area for future research.

If confirmed with longitudinal and interventional studies, the key to prevention of $\mathrm{MCI}$ and subsequent dementia may be to strengthen a multidisciplinary approach simultaneously targeting lifestyle factors and physical health outcomes (e.g., chronic diseases, multimorbidity). Health promotion can specifically target risk factors contributing to chronic physical conditions and ultimately multimorbidity, which might include diet, exercise, and smoking cessation, all of which are also considered to be important for dementia prevention even in the absence of chronic physical conditions. ${ }^{16}$

To address chronic diseases in LMICs, the WHO Innovative Care for Chronic Conditions framework provides a health systems roadmap, but it does not incorporate the complexity associated with multimorbidity. ${ }^{51}$ In LMICs, there is a particular need to enhance integration of care and capacity building and to improve quality of services to address multimorbidity. ${ }^{52}$

The study results should be interpreted in the light of several limitations. First, although we included a wide variety of important chronic conditions, we lacked data on diseases such as hypercholesterolemia and human immunodeficiency virus infection. Second, symptom-based algorithms were used to define some chronic conditions to minimize underdiagnosis, but there may still be some level of misclassification, and underdiagnosis is likely to have occurred for diseases based solely on self-report (diabetes mellitus, stroke). For example, chronic lung diseases and asthma are not easy to differentiate for the overlapping symptoms, especially in older populations. ${ }^{53}$ Third, because the study was not designed to generate clinical diagnoses of dementia, some individuals with mild dementia may have been included in our analytical sample, although the prevalence of MCI in our study was within previously reported figures. ${ }^{54}$ Furthermore, in line with previous publications, ${ }^{9,22}$ we used a definition for preservation of independence in functional abilities based on only $2 \mathrm{ADL}$ domains so as not to overexclude MCI cases with disability not related to their cognitive ability. There is no consensus in terms of the acceptable level of functional impairment that individuals with MCI could have, ${ }^{55}$ but it is reassuring that the results were similar even when applying a different definition of disability (impairment in all 6 ADL domains ${ }^{25}$ ). Furthermore, we lacked data on dietary factors, medication, and past alcohol drinking patterns, which may also explain the link between chronic conditions and MCI. Next, the response rate for the SAGE survey was comparable with or higher than that of other national surveys on aging in most of the countries included in our study. Nevertheless, there was some between-country variability, and the response rate for Mexico was low. Finally, because this was a cross-sectional study, causality cannot be inferred, and the possibility of reverse causality cannot be dismissed.

In conclusion, several chronic conditions and multimorbidity were found to be associated with MCI. Our study results highlight the need to investigate the underlying mechanisms linking chronic conditions and MCI and whether prevention or treatment of chronic conditions or multimorbidity can reduce the onset of cognitive decline and subsequent dementia, especially in LMICs.

\section{ACKNOWLEDGMENTS}

Financial Disclosure: AK's work was supported by the Miguel Servet contract financed by the CP13/00150 and PI15/00862 projects, integrated into the National $\mathrm{R}+\mathrm{D}+\mathrm{I}$ and funded by the ISCIII-General Branch Evaluation and Promotion of Health Research-and the European Regional Development Fund. BS receives funding from the National Institutes of Health (NIH) Research Collaboration for Leadership in Applied Health Research \& Care Funding scheme. HO receives funding from Grant T32AA014125 from the National Institute on Alcohol Abuse and Alcoholism (NIAAA) of NIH. The content is solely the responsibility of the authors and does not necessarily represent the official views of National Health Service, the National Institute for Health Research, Department of Health, NIAAA, or NIH.

Conflict of Interest: None.

Author Contributions: AK: study concept. AK, EL, BS, DV: data analysis and interpretation. AK: writing main body of text. All authors: manuscript preparation, data interpretation, comments on intellectual content. All authors read and approved the final manuscript.

Sponsor's Role: None of the funders had any role in the conduct of the study; collection, management, analysis, or interpretation of the data; or preparation, review, or approval of the manuscript.

\section{REFERENCES}

1. Global Health and Ageing. Geneva, Switzerland: World Health Organization, 2011.

2. Mathers CD, Loncar D. Projections of global mortality and burden of disease from 2002 to 2030. PLoS Med 2006;3:e442.

3. World Alzheimer Report. London, UK: Alzheimer Disease International, 2015.

4. Wimo A, Guerchet M, Ali GC et al. The worldwide costs of dementia 2015 and comparisons with 2010. Alzheimers Dement 2017;13:1-7.

5. Cummings JL. Treatment of Alzheimer's disease: Current and future therapeutic approaches. Rev Neurol Dis 2004;1:60-69.

6. Kaduszkiewicz H, Zimmermann T, Beck-Bornholdt HP, van den Bussche H. Cholinesterase inhibitors for patients with Alzheimer's disease: systematic review of randomised clinical trials. BMJ 2005;331:321-327. 
7. Petersen RC, Smith GE, Waring SC, Ivnik RJ, Tangalos EG, Kokmen E. Mild cognitive impairment: Clinical characterization and outcome. Arch Neurol 1999;56:303-308.

8. Solfrizzi V, Panza F, Colacicco AM et al. Vascular risk factors, incidence of MCI, and rates of progression to dementia. Neurology 2004;63:1882-1891.

9. Lara E, Koyanagi A, Olaya B et al. Mild cognitive impairment in a Spanish representative sample: Prevalence and associated factors. Int J Geriatr Psychiatry 2016;31:858-867.

10. Biessels GJ, Staekenborg S, Brunner E, Brayne C, Scheltens P. Risk of dementia in diabetes mellitus: A systematic review. Lancet Neurol 2006;5:64-74.

11. Marengoni A, Angleman S, Melis R et al. Aging with multimorbidity: A systematic review of the literature. Ageing Res Rev 2011;10:430-439.

12. Violan C, Foguet-Boreu Q, Flores-Mateo G et al. Prevalence, determinants and patterns of multimorbidity in primary care: A systematic review of observational studies. PLoS One 2014;9:e102149.

13. Vassilaki M, Aakre JA, Cha RH et al. Multimorbidity and risk of mild cognitive impairment. J Am Geriatr Soc 2015;63:1783-1790.

14. Frisoni GB, Fratiglioni L, Fastbom J, Guo Z, Viitanen M, Winblad B. Mild cognitive impairment in the population and physical health: Data on 1,435 individuals aged 75 to 95. J Gerontol A Biol Sci Med Sci 2000;55A:M322-M328.

15. Amieva H, Jacqmin-Gadda H, Orgogozo JM et al. The 9 year cognitive decline before dementia of the Alzheimer type: A prospective populationbased study. Brain 2005;128:1093-1101.

16. World Alzheimer Report. London, UK: Alzheimer Disease International, 2014.

17. Kivipelto M, Ngandu T, Laatikainen T, Winblad B, Soininen H, Tuomilehto J. Risk score for the prediction of dementia risk in 20 years among middle aged people: A longitudinal, population-based study. Lancet Neurol 2006;5:735-741.

18. Gottesman RF, Albert MS, Alonso A et al. Associations between midlife vascular risk factors and 25-year incident dementia in the Atherosclerosis Risk in Communities (ARIC) cohort. JAMA Neurol 2017;74:1246-1254

19. G. B. D. Healthcare Access Quality Collaborators. Healthcare Access and Quality Index based on mortality from causes amenable to personal health care in 195 countries and territories, 1990-2015: A novel analysis from the Global Burden of Disease Study 2015. Lancet 2017;390:231-266.

20. Kowal P, Chatterji S, Naidoo N et al. Data resource profile: The World Health Organization Study on global AGEing and adult health (SAGE). Int J Epidemiol 2012;41:1639-1649.

21. Albert MS, DeKosky ST, Dickson D et al. The diagnosis of mild cognitive impairment due to Alzheimer's disease: Recommendations from the National Institute on Aging-Alzheimer's Association workgroups on diagnostic guidelines for Alzheimer's disease. Alzheimers Dement 2011;7:270-279.

22. Lara E, Koyanagi A, Domenech-Abella J, Miret M, Ayuso-Mateos JL, Haro JM. The impact of depression on the development of mild cognitive impairment over 3 years of follow-up: A population-based study. Dement Geriatr Cogn Disord 2017;43:155-169.

23. Morris JC, Heyman A, Mohs RC et al. The Consortium to Establish a Registry for Alzheimer's Disease (CERAD). Part I. Clinical and neuropsychological assessment of Alzheimer's disease. Neurology 1989;39:1159-1165.

24. The WAIS III-WMS III Updated Technical Manual. San Antonio, TX: The Psychological Corporation, 2002.

25. Katz S, Ford AB, Moskowitz RW, Jackson BA, Jaffe MW. Studies of illness in the aged. The index of ADL: A standardized measure of biological and psychosocial function. JAMA 1963;185:914-919.

26. Fortunato S, Forli F, Guglielmi V et al. A review of new insights on the association between hearing loss and cognitive decline in ageing. Acta Otorhinolaryngol Ital 2016;36:155-166.

27. Caldera-Alvarado G, Khan DA, Defina LF, Pieper A, Brown ES. Relationship between asthma and cognition: The Cooper Center Longitudinal Study. Allergy 2013;68:545-548.

28. Cerutti-Kopplin D, Feine J, Padilha DM et al. Tooth loss increases the risk of diminished cognitive function. JDR Clin Translat Res 2016;1:10-19.

29. Singh B, Parsaik AK, Mielke MM et al. Chronic obstructive pulmonary disease and association with mild cognitive impairment: The Mayo Clinic Study of Aging. Mayo Clin Proc 2013;88:1222-1230.

30. Veeranki SP, Downer B, Jupiter D, Wong R. Arthritis and risk of cognitive and functional impairment in older Mexican adults. J Aging Health 2017;29:454-473.

31. Sierra C, Domenech M, Camafort M, Coca A. Hypertension and mild cognitive impairment. Curr Hypertens Rep 2012;14:548-555.

32. Eggermont LH, de Boer K, Muller M, Jaschke AC, Kamp O, Scherder EJ. Cardiac disease and cognitive impairment: A systematic review. Heart 2012;98:1334-1340.

33. Jefferis JM, Mosimann UP, Clarke MP. Cataract and cognitive impairment: A review of the literature. Br J Ophthalmol 2011;95:17-23.

34. Garin N, Koyanagi A, Chatterji S et al. Global multimorbidity patterns: A cross-sectional, population-based, multi-country study. J Gerontol A Biol Sci Med Sci 2016;71A: 205-214.
35. World Health Organization. Chronic Diseases and Their Common Risk Factors [on-line] Available at http://www.who.int/chp/chronic_disease_ report/media/Factsheet1.pdf Accessed 31 August 2017.

36. Voinov B, Richie WD, Bailey RK. Depression and chronic diseases: It is time for a synergistic mental health and primary care approach. Prim Care Companion CNS Disord 2013;15.

37. Baumgart M, Snyder HM, Carrillo MC, Fazio S, Kim H, Johns H. Summary of the evidence on modifiable risk factors for cognitive decline and dementia: A population-based perspective. Alzheimers Dement 2015;11:718-726.

38. Higgins JP, Thompson SG, Deeks JJ, Altman DG. Measuring inconsistency in meta-analyses. BMJ 2003;327:557-560.

39. mhGAP Intervention Guide for Mental, Neurological and Substance Use Disorders in Non-Specialized Health Settings. Geneva, Switzerland: World Health Organization, 2017.

40. Gaziano TA, Pagidipati N. Scaling up chronic disease prevention interventions in lower- and middle-income countries. Annu Rev Public Health 2013;34:317-335.

41. Gorelick PB, Scuteri A, Black SE et al. Vascular contributions to cognitive impairment and dementia: A statement for healthcare professionals from the American Heart Association/American Stroke Association. Stroke 2011; 42:2672-2713.

42. Verghese J, Annweiler C, Ayers E et al. Motoric cognitive risk syndrome: Multicountry prevalence and dementia risk. Neurology 2014;83:718-726.

43. Prince M, Acosta D, Ferri CP et al. The association between common physical impairments and dementia in low and middle income countries, and, among people with dementia, their association with cognitive function and disability. A 10/66 Dementia Research Group population-based study. Int J Geriatr Psychiatry 2011;26:511-519.

44. Hong T, Mitchell P, Burlutsky G, Liew G, Wang JJ. Visual impairment, hearing loss and cognitive function in an older population: Longitudinal findings from the Blue Mountains Eye Study. PLoS One 2016;11:e0147646.

45. Dodd JW. Lung disease as a determinant of cognitive decline and dementia. Alzheimers Res Ther 2015;7:32.

46. Hebert LE, Scherr PA, Bennett DA et al. Blood pressure and late-life cognitive function change: A biracial longitudinal population study. Neurology 2004;62:2021-2024.

47. Panza F, Capurso C, D'Introno A et al. Impact of depressive symptoms on the rate of progression to dementia in patients affected by mild cognitive impairment. The Italian Longitudinal Study on Aging. Int J Geriatr Psychiatry 2008;23:726-734.

48. Fabbri E, An Y, Zoli M et al. Association between accelerated multimorbidity and age-related cognitive decline in older Baltimore Longitudinal Study of Aging participants without dementia. J Am Geriatr Soc 2016;64:965-972.

49. Song X, Mitnitski A, Rockwood K. Nontraditional risk factors combine to predict Alzheimer disease and dementia. Neurology 2011;77:227-234.

50. Fratiglioni L, Paillard-Borg S, Winblad B. An active and socially integrated lifestyle in late life might protect against dementia. Lancet Neurol 2004;3:343-353.

51. Oni T, McGrath N, BeLue R et al. Chronic diseases and multi-morbiditya conceptual modification to the WHO ICCC model for countries in health transition. BMC Public Health 2014;14:575.

52. Navickas R, Petric VK, Feigl AB, Seychell M. Multimorbidity: What do we know? What should we do? J Comorb 2016;6:8.

53. To T, Stanojevic S, Moores G et al. Global asthma prevalence in adults: Findings from the cross-sectional World Health Survey. BMC Public Health 2012;12:204.

54. Petersen RC. Mild cognitive impairment. Continuum (Minneap Minn) 2016;22:404-418.

55. Lindbergh CA, Dishman RK, Miller LS. Functional disability in mild cognitive impairment: A systematic review and meta-analysis. Neuropsychol Rev 2016;26:129-159.

\section{SUPPORTING INFORMATION}

Additional Supporting Information may be found in the online version of this article.

Table S1. Details of variables and additional analyses

Please note: Wiley-Blackwell is not responsible for the content, accuracy, errors, or functionality of any supporting materials supplied by the authors. Any queries (other than missing material) should be directed to the corresponding author for the article. 